\title{
Ion-Exchange Membranes Based on Polynorbornenes with Fluorinated Imide Side Chain Groups
}

\author{
Arlette A. Santiago, ${ }^{1}$ Joel Vargas, ${ }^{2}$ Mikhail A. Tlenkopatchev, ${ }^{3}$ \\ Mar López-González, ${ }^{4}$ and Evaristo Riande ${ }^{4}$ \\ ${ }^{1}$ Facultad de Química, Universidad Nacional Autónoma de México, CU, Coyoacán, 04510 México, DF, Mexico \\ ${ }^{2}$ Facultad de Ingeniería, Universidad Autónoma del Carmen, Avenida Central S/N Esq. con Fracc. Mundo Maya, \\ 24115 Ciudad del Carmen, CAM, Mexico \\ ${ }^{3}$ Instituto de Investigaciones en Materiales, Universidad Nacional Autónoma de México, CU, Apartado Postal 70-360, \\ Coyoacán, 04510 México, DF, Mexico \\ ${ }^{4}$ Instituto de Ciencia y Tecnología de Polimeros (ICTP-CSIC), C/Juan de la Cierva 3, 28006 Madrid, Spain
}

Correspondence should be addressed to Mikhail A. Tlenkopatchev, tma@unam.mx

Received 3 February 2012; Revised 11 April 2012; Accepted 15 April 2012

Academic Editor: Seung Hyeon Moon

Copyright (C) 2012 Arlette A. Santiago et al. This is an open access article distributed under the Creative Commons Attribution License, which permits unrestricted use, distribution, and reproduction in any medium, provided the original work is properly cited.

The electrochemical characteristics of cation-exchange membranes based on polynorbornenes with fluorinated and sulfonated dicarboximide side chain groups were reported. This study was extended to a block copolymer containing structural units with phenyl and 4-oxybenzenesulfonic acid, 2,3,5,6-tetrafluorophenyl moieties replacing the hydrogen atom of the dicarboximide group. A thorough study on the electrochemical characteristics of the membranes involving electromotive forces of concentration cells and proton conductivity is reported. The proton permselectivity of the membranes is also discussed.

\section{Introduction}

Ion-exchange membranes have received considerable attention for many applications. Thus, the desalination of seawater and brackish-water, treatment of industrial effluents, concentration or separation of food and pharmaceutical products containing ionic species are some of the examples of these kinds of applications [1,2].

Ion-exchange membranes should exhibit high conductance, high permselectivity, low free diffusion of ionic species, low osmotic flow, good mechanical properties, and high chemical stability. Many polyelectrolytes based on perfluorinated polyimides, polyetherketones, polysulfones, polyphosphazenes; have been synthesized, and their electrochemical characteristics have been studied [3]. It is well known that norbornene monomers can be easily functionalized and membranes from functionalized polynorbornenes with adamantyl, phenyl, cyclohexyl, and pentafluorophenyl dicarboximide side groups have been prepared [4-6]. Taking into account these antecedents and searching for new ionexchange membranes, a study was undertaken focused on the preparation of cation-exchange membranes based on modified polynorbornenes.

In an earlier work, the preparation of hydrogenated and sulfonated poly( $N$-phenyl-exo-endo-norbornene-5,6dicarboximide) has been reported [7]. A drawback of these membranes is that the sulfonation procedure does not guarantee a uniform sulfonation of the phenyl groups, and even it can produce degradative processes in the polymer chains. In order to circumvent these difficulties, we have synthesized poly $(N$-pentafluorophenyl-exo-endonorbornene-5,6-dicarboximide) and successfully replaced the fluorine atom in position 4 of the phenyl group by sulfonation in mild conditions [8].

The fluorine atoms in the polyelectrolyte side chains can decrease attractive intermolecular interactions between phenyl groups thus avoiding the molecular piling of the phenyl rings. This behavior is a direct consequence of the 
high electronegativity of the fluorine atom which severely reduces the polarizability of the $\mathrm{C}^{\mathrm{ar}}-\mathrm{F}$ bond and as a result the formation of nonpermanent or flitting dipoles which are the basis of the London dispersion forces [9]. It should be noted that earlier studies on gas transport in polynorbornenebased membranes showed that fluorinated moieties in the polymer chains cause a significant increase in gas permeability as a consequence of the decrease in intramolecular interactions [10]. The cation-exchange membranes were also prepared from copolymers resulting from partially replacing the phenyl groups of poly ( $N$-phenyl-exo-endo-norbornene5,6-dicarboximide) by 4-oxybenzenesulfonic acid, 2,3,5,6tetrafluorophenyl groups [11]. The aim of this study was to find out how the decrease of the density of sulfonic acid in the membranes affects their transport characteristics. The acronyms used for the homopolymeric and the copolymeric acidic membranes were, respectively, P5FNDIHS and C5FNDIHS, and the structural units of the respective chains are shown in Figure 1.

\section{Experimental Part}

2.1. Synthesis of the Monomer. By reaction of norbornene5,6-dicarboxylic anhydride (NDA) with 2,3,4,5,6-pentafluoroaniline an amic acid (AA) that is obtained which further treated with anhydrous sodium acetate/acetic anhydride produces the monomer $\mathrm{N}$-pentafluorophenyl-exo-endonorbornene-5,6-dicarboximide (5FNDI) (see Scheme 1). More details of the synthesis are given elsewhere [8].

2.2. Polymerization. Polymerization of 5FNDI was carried out by ring opening metathesis polymerization (ROMP) (Scheme 1). The reaction was performed at $45^{\circ} \mathrm{C}$ for $2 \mathrm{~h}$ in glass vials, under nitrogen atmosphere. The polymerization was terminated by adding ethyl vinyl ether to the reaction medium which was further poured into methanol, solubilized with chloroform containing a few drops of $1 \mathrm{~N} \mathrm{HCl}$, and precipitated again into methanol. The product was dried in a vacuum oven at $40^{\circ} \mathrm{C}$ to constant weight. Then, the polymer was hydrogenated quantitatively at room temperature and 115 bar using a Wilkinson's catalyst (Scheme 2).

2.3. Sulfonation Procedure. Hydrogenated poly(N-pentafluorophenyl-norbornene-5,6-dicarboximide) (P5FNDIH) $(0.5 \mathrm{~g}, \quad 1.51 \mathrm{mmol})$, sodium 4-hydroxybenzenesulfonate dihydrate $(0.70 \mathrm{~g}, 3.02 \mathrm{mmol})$, and potassium carbonate $(0.52 \mathrm{~g}, 3.77 \mathrm{mmol})$ were mixed in a round flask equipped with a Dean-Stark trap and stirred in $15 \mathrm{~mL}$ of solvent $(N, N$-dimethylacetamide-toluene $2: 1)$ at $120^{\circ} \mathrm{C}$ for $9 \mathrm{~h}$ (Scheme 2). Progressive precipitation overtime was observed. The product was then filtered off, washed several times with distilled water and dried in a vacuum oven at $40^{\circ} \mathrm{C}$ overnight. The resulting polymer P5FNDIHS, a pale-brown powder, was soluble in DMF and DMSO. Yield: $94 \%, T_{g}=228^{\circ} \mathrm{C}, T_{d 1}=260^{\circ} \mathrm{C}$ (sulfonic group loss), $T_{d 2}=$ $430^{\circ} \mathrm{C}$ (main chain decomposition).
${ }^{1} \mathrm{H}$ NMR $\left(300 \mathrm{MHz}\right.$, DMF- $\left.d_{7}\right): \delta(\mathrm{ppm})=7.80(2 \mathrm{H}, \mathrm{s})$, $7.18(2 \mathrm{H}, \mathrm{s}), 3.56(2 \mathrm{H}, \mathrm{s}), 2.73,2.31,1.83,1.58,1.91$.

${ }^{13} \mathrm{C}$ NMR $\left(75 \mathrm{MHZ}, \mathrm{DMF}-d_{7}\right): \delta(\mathrm{ppm})=175.0(\mathrm{C}=\mathrm{O})$, 145.5, 145.0, 140.4, 139.7, $128.2(\mathrm{C}-\mathrm{O}), 115.1,107.2,49.0$, 43.0.

${ }^{19} \mathrm{~F}$ NMR (300 MHz, DMSO- $d_{6}$, ref. TFA [-77 ppm]): $\delta$ $(\mathrm{ppm})=-141.9,-143.0,-153.1$.

FT-IR (thin film, $\mathrm{cm}^{-1}$ ): 2926 (C-H asym str), 2860 (CH sym str), 1787 (C=O), 1726, 1636, 1509, 1406, 1356, 1295 $(\mathrm{C}-\mathrm{F}), 1140\left(-\mathrm{SO}_{3} \mathrm{H}\right.$, asym str), 1132, $1039\left(-\mathrm{SO}_{3} \mathrm{H}\right.$, sym str), 981, 833, 698, 561. The acronym for this polymer will be P5FNDIHS (Figure 1).

2.4. Copolymerization. The copolymer was prepared via ROMP in a block fashion [11]. Firstly, monomer PhNDI, synthesized according to literature [8] and catalyst I were stirred in 1,2 -dichloroethane at $65^{\circ} \mathrm{C}$ for $0.33 \mathrm{~h}$. Then, monomer 5FNDI dissolved in 1,2-dichloroethane was added to the polymer solution and stirred at $65^{\circ} \mathrm{C}$ for $0.66 \mathrm{~h}$ (Scheme 1). The obtained copolymer C5FNDI was soluble in chloroform and dichloroethane. The incorporation of 5FNDI in copolymer was $32 \mathrm{~mol} \%$ as determined by ${ }^{1} \mathrm{H}$ NMR. The block copolymer obtained was hydrogenated as mentioned above and the pentafluorophenyl moieties of hydrogenated poly ( $N$-phenyl-exo-endo-norbornene-5,6dicarboximide- $c o-N$-pentafluorophenyl-exo-endo-norbornene-5,6-dicarboximide) (C5FNDIH) were sulfonated with 4hydroxybenzenesulfonate dihydrate using the procedure used for the sulfonation of hydrogenated poly $(N$-pentafluorophenyl-exo-endo-norbornene-5,6-dicarboximide) (Scheme 2). The acronym for this copolymer will be C5FNDIHS and its composition is shown in Figure 1.

2.5. Membranes Preparation and Atomic Force Microscopy (AFM). P5FNDIHS and C5FNDIHS membranes (in sodium salt form) were cast, respectively, from hot $N, N$-dimethylformamide solutions ( $\sim 2 \mathrm{wt} \%)$ of P5FNDIHS and C5FNDIHS chains in a Teflon mold and dried at $70^{\circ} \mathrm{C}$ for $12 \mathrm{~h}$. The films were immersed firstly in stirring methanol at room temperature for $3 \mathrm{~h}$ and secondly in deionized water for $1 \mathrm{~h}$ in order to remove the residual solvent. Afterwards, the membranes underwent a proton exchange treatment with $1.0 \mathrm{~N}$ hydrochloric acid during $12 \mathrm{~h}$. Then, the films were washed repeatedly with deionized water until the rinse water became neutral. Finally, the membranes were dried under a vacuum at $120^{\circ} \mathrm{C}$ for $10 \mathrm{~h}$.

The surface morphology of the thin films was observed using tapping mode AFM (Multimode Nanoscope IVa, Digital Instrument/Veeco) under ambient conditions. In tapping mode, the stylus oscillates and touches the sample only at the end of its downward movement. The nominal resonance frequency for the tapping mode was between 265$309 \mathrm{kHz}$ with a phosphorous $(n)$ doped Si cantilever which had a spring constant that ranged from 20 to $80 \mathrm{~N} \mathrm{~m}^{-1}$. The set point in the AFM control program was adjusted to change the contact force between the tip and surface in order to detect the existence of morphologies. 
<smiles>CC(C)(C)CC1CC(C(C)(C)C)C2C(=O)N(c3c(F)c(F)c(Oc4ccc(S(=O)(=O)O)cc4)c(F)c3F)C(=O)C12</smiles>

P5FNDIHS

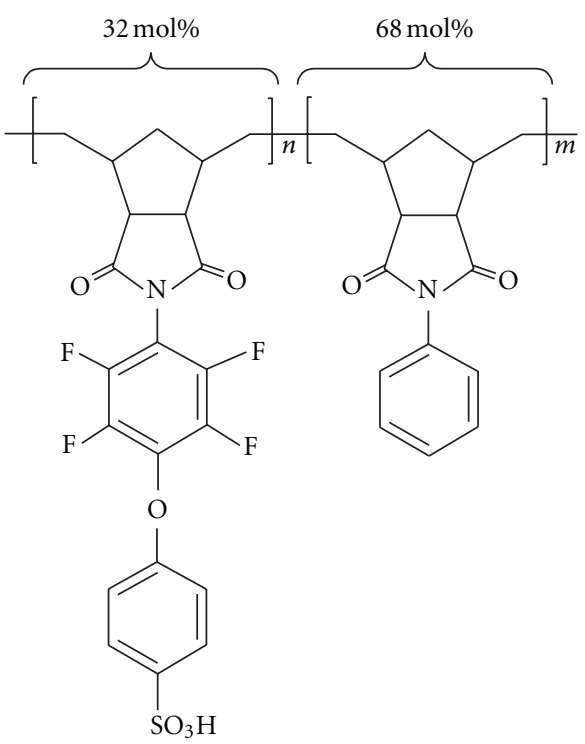

C5FNDIHS

FIGURE 1: Acid form structural units of hydrogenated-sulfonated poly( $N$-pentafluorophenyl-exo-endo-norbornene-5,6-dicarboximide) (P5FNDIHS) and hydrogenated-sulfonated poly( $N$-phenyl-exo-endo-norbornene-5,6-dicarboximide-co- $N$-pentafluorophenyl-exo-endonorbornene-5,6-dicarboximide) (C5FNDIHS).<smiles>Nc1c(F)c(F)c(F)c(F)c1CCC(=O)C1C2C=CC(C2)C1C(=O)Nc1c(F)c(F)c(F)c(F)c1F</smiles><smiles>CCOC(C)OC(C)OCC</smiles><smiles>O=C1ONC(=O)[C@H]2C3C=CC(C3)C12</smiles><smiles>CC(C)(C)C1CC(C(C)(C)C)C2C(=O)N(c3c(F)c(F)c(F)c(F)c3F)C(=O)C21</smiles><smiles>O=C1C2CC(C(=O)N1c1c(F)c(F)c(F)c(F)c1F)[C@H]1C=C[C@H]2C1</smiles>

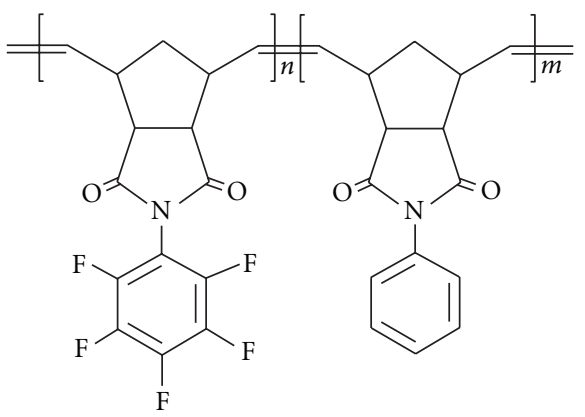

P5FNDI 5FNDI 
<smiles>O=C1C(=O)N(c2c(F)c(F)c(F)c(F)c2F)C(=O)C2CC(C3CC3)CC(CC3CC3)C12</smiles>

P5FNDI<smiles>CC(C)(C)CC1CC(Cc2ccccc2)C2C(=O)N(c3c(F)c(F)c(F)c(F)c3F)C(=O)C12</smiles>

P5FNDIH<smiles>CC(C)(C)CC1C(Cc2ccccc2)CC2C1C(=O)N(c1c(F)c(F)c(Oc3ccc(S(N)(=O)=O)cc3)c(F)c1F)C2(C)C</smiles>

P5FNDIHS

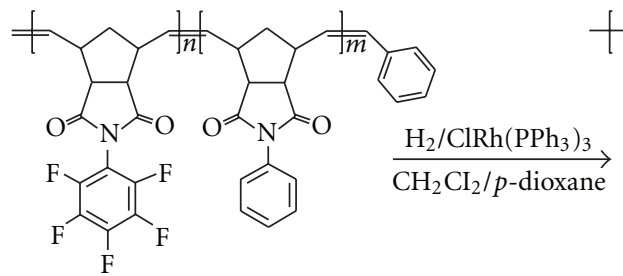

C5FNDI
$\underset{\mathrm{CH}_{2} \mathrm{CI}_{2} / p \text {-dioxane }}{\stackrel{\mathrm{H}_{2} / \mathrm{ClRh}\left(\mathrm{PPh}_{3}\right)_{3}}{\longrightarrow}}$<smiles>CC(C)(C)C1CC(C(C)(C)C)C2C(=O)N(c3c(F)c(F)c(F)c(F)c3F)C(=O)C21</smiles>

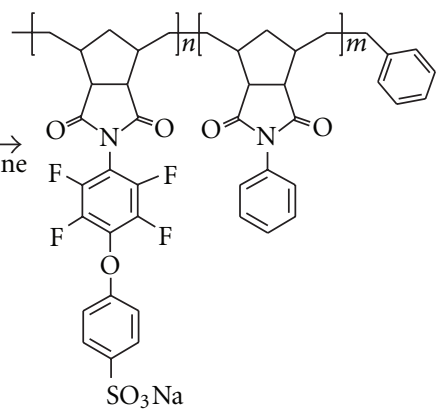

C5FNDIHS

Scheme 2: Synthesis of sulfonated polymer and copolymer.

TABle 1: Density in $\mathrm{Kg} \mathrm{m}^{-3}, \rho$, water uptake in $\mathrm{Kg} \mathrm{H}_{2} \mathrm{O} / \mathrm{Kg}$ dry membrane, $w_{u}$, IEC in equivalents of fixed anionic groups per $\mathrm{Kg}$ dry membrane obtained by titration, $X^{-}$, and NMR, $X_{\mathrm{NMR}}^{-}$, molecules of water per fixed ionic group, $\lambda$, and conductivity, $\sigma$, in $\mathrm{S} / \mathrm{m}$, at $30^{\circ} \mathrm{C}$.

\begin{tabular}{lccccccc}
\hline Membrane & $\rho$ & $w_{u}$ & $X^{-}$ & $X_{\text {NMR }}^{-}$ & $\lambda_{x^{-}}$ & $\lambda X_{\text {NMR }}^{-}$ & 16.6 \\
\hline P5FNDIHS & 1500 & 0.617 & 1.750 & 2.060 & 19.6 & 2.24 \\
C5FNDIHS & 1380 & 0.373 & 0.286 & 0.204 & 72.5 & 101.6 & 0.0134 \\
\hline
\end{tabular}

2.6. Density, Water Uptake, and Ion-Exchange Capacity of the Membranes. The density of the dry membranes was measured by the flotation method using isooctane as solvent. The values of this parameter are shown in the first column of Table 1.

Weighed dry membranes were immersed in distilled water for several hours, removed from the solution, gently blotted with filter paper to remove superficial water, and weighed. From the weights of the dry membranes, $m_{d}$, and the membranes equilibrated with water, $m_{w}$, the water uptake, $w_{u}$, in $\mathrm{g} \mathrm{H}_{2} \mathrm{O} / \mathrm{g}$ dry membrane is obtained as $w_{u}=$ $\left(m_{w} / m_{d}\right)-1$.

The ion-exchange capacity (IEC) of a given membrane was measured by immersing the weighed dry membrane in a $1 \mathrm{~N} \mathrm{HCl}$ solution for $1 \mathrm{~h}$. Then the membrane was removed from the solution, washed several times with distilled water to eliminate the chloride acid absorbed, and finally immersed in a $1 \mathrm{~N}$ sodium chloride solution. The protons exchanged in the reaction

$$
\mathrm{R}-\mathrm{H}+\mathrm{Na}^{+} \longrightarrow \mathrm{R}-\mathrm{Na}+\mathrm{H}^{+}
$$

were estimated by titration with a very diluted $\mathrm{NaOH}$ solution. The values of IEC in equiv/Kg dry membrane were obtained as IEC $=V N / m_{d}$ where $V$ is the volume in $L$ of the solution of $\mathrm{NaOH}$ of normality $N$ (equiv/L) used in the titration, and $m_{d}$ is the mass of the membrane in $\mathrm{Kg}$.

2.7. Electromotive Forces of Concentration Cells. Electromotive forces of concentration cells made up of two semicells separated by the ion-exchange membrane were measured (Figure 2). The configuration of the cells was $\mathrm{Ag}|\mathrm{AgCl}| \mathrm{HCl}$ solution $\left(c_{1}\right)$ |cation-exchange membrane $\mathrm{HCl}$ solution $\left(c_{2}\right)|\mathrm{AgCl}| \mathrm{Ag}$, where $c_{1}$ and $c_{2}$ are the concentrations of the electrolyte in the left-hand and right-hand compartments of the concentration cells. Notice that the anion of the electrolyte must be reversible with that of the electrodes. The solution in each compartment was kept under strong stirring to minimize the formation of membrane-solution interface layers. The evolution of electromotive force, emf, of the cell with time was measured at $25^{\circ} \mathrm{C}$ with a 3645 20 Hioki voltage logger and recorded every second with a 3911-20 communication base apparatus via a PC. The emf 


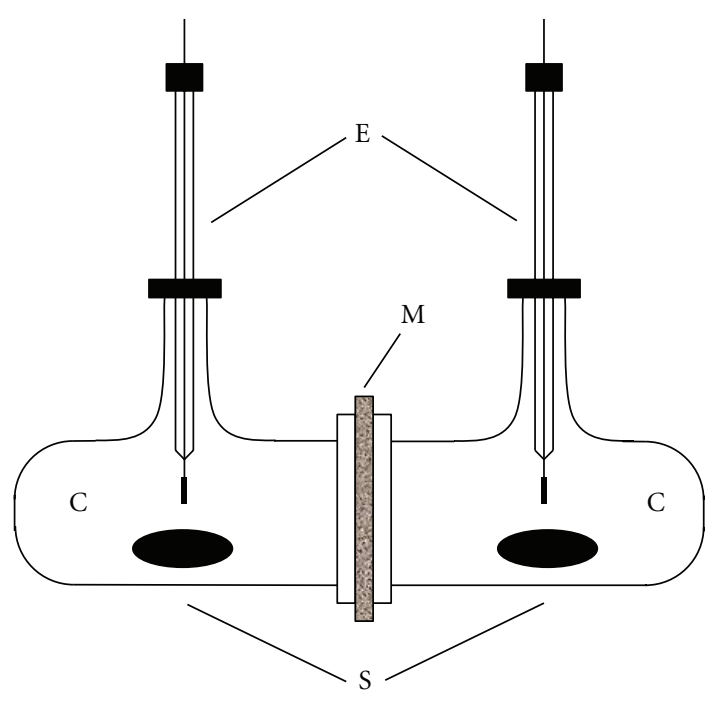

Figure 2: Concentration cell used to measure the electromotive force: (C) half cell, (E) electrodes, (M) ion-exchange membrane, and $(\mathrm{S})$ magnetic stirrers.

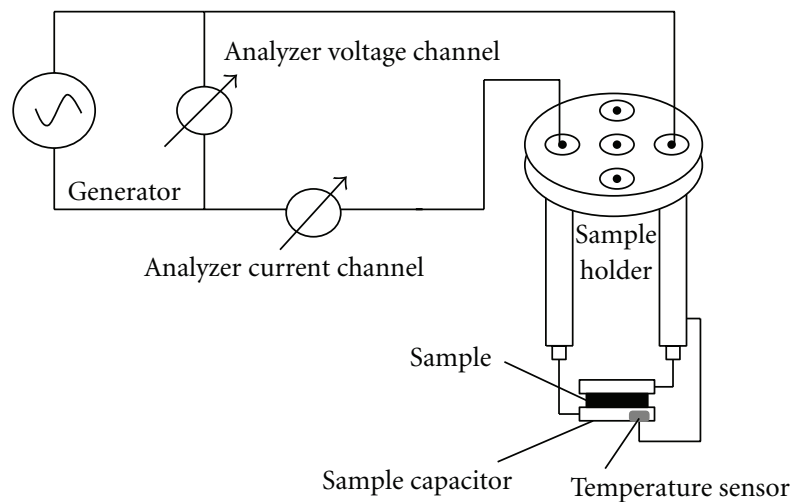

Figure 3: Cell used to measure the ionic conductivity of the membranes.

of the concentration cell was taken as that one at which this quantity reaches a maximum.

2.8. Ohmic Resistance Measurements. The ohmic resistance of the membranes in the acid form was measured with a Novocontrol BDS system comprising a frequency response analyzer (Solartron Schlumberger FRA 1260) and a broadband dielectric converter with an active sample head. Gold disk electrodes were used in the impedance measurements carried out at several temperatures in the frequency window $4.9 \times 10^{-2}-1 \times 10^{7} \mathrm{~Hz}$. The temperature was controlled by a nitrogen jet (QUATRO from Novocontrol) with a temperature error of $0.1 \mathrm{~K}$ during every single sweep in frequency (Figure 3). Measurements were carried out on molded disk-shaped samples of $60-100 \mu \mathrm{m}$ thickness with diameters of 20 and $10 \mathrm{~mm}$.

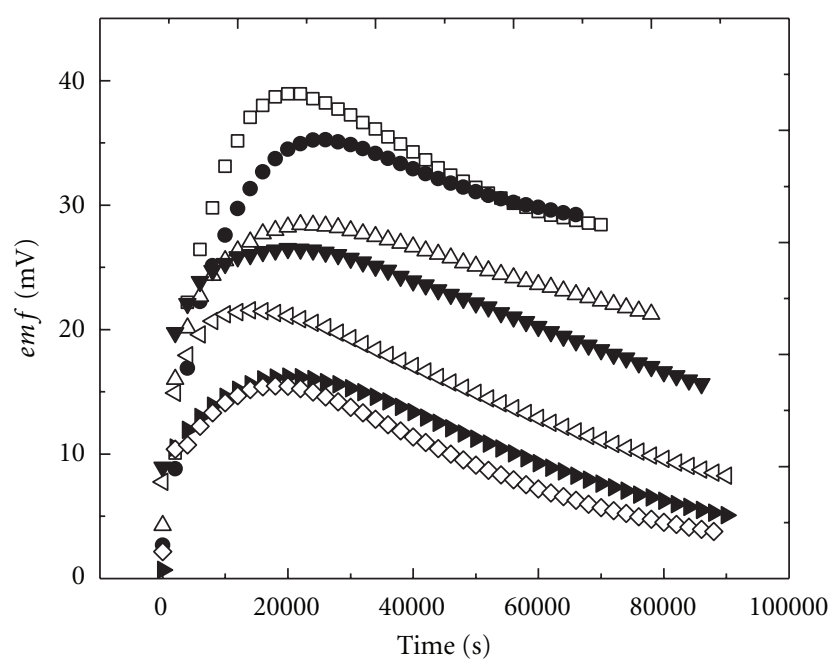

Figure 4: Evolution of the emf of the P5FNDIHS membrane for different $c_{2} / c_{1}$ ratios: $(\square) 0.01 / 0.005,(\bullet) 0.02 / 0.01,(\triangle) 0.1 / 0.05$, $(\nabla) 0.2 / 0.1,(\triangleleft) 0.4 / 0.2,(\triangleright) 0.8 / 0.4$, and $(\diamond)$ 1.0/0.5.

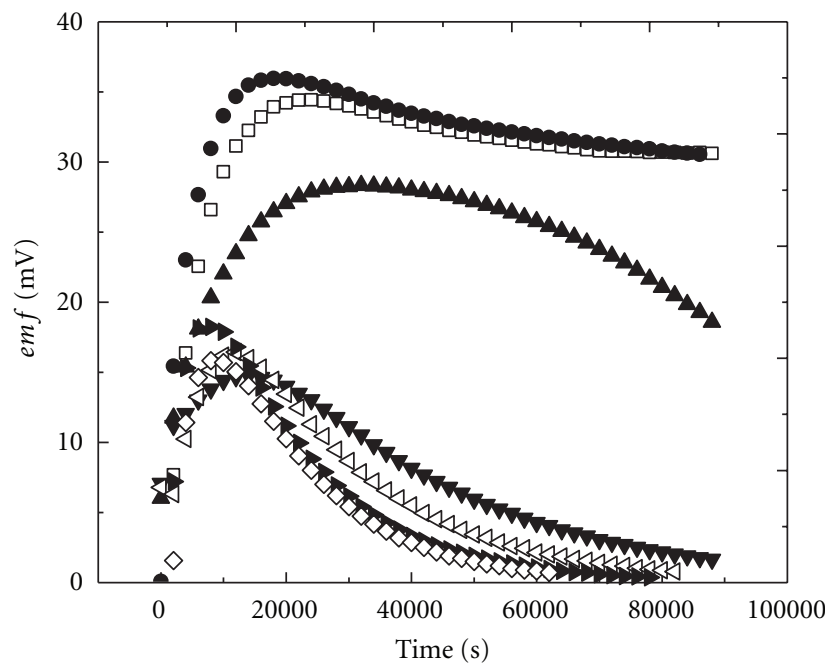

FIGURE 5: Evolution of the emf of the C5FNDIHS membrane for different $c_{2} / c_{1}$ ratios: $(\square) 0.01 / 0.005,(\bullet) 0.02 / 0.01,(\boldsymbol{\Delta}) 0.1 / 0.05$, $(\boldsymbol{\nabla}) 0.2 / 0.1,(\triangleleft) 0.4 / 0.2,(\triangleright) 0.8 / 0.4$, and $(\diamond)$ 1.0/0.5.

\section{Results and Discussion}

Values of the water uptake and the ion-exchange capacity (IEC) of the membranes measured by titration are given in Table 1. The values of the IEC estimated from the NMR spectra, also given in Table 1, somewhat differ from those determined by titration. Moreover, the number of moles of water per $-\mathrm{SO}_{3}{ }^{-}$group anchored to the polymer chains of the membranes are also shown in Table 1. It is worth noting that in spite of its relatively low IEC, the C5FNDIHS membrane exhibits a rather large number of molecules of water per anionic fixed group.

The variation of the electromotive force, emf, of the concentration cell with time for several $\mathrm{HCl}$ solutions flanking the membrane of interest is shown in Figures 4 and 5. 
The ratio between the concentrations of the solutions in the concentrated, $c_{2}$, and diluted, $c_{1}$, compartments lies in the vicinity of 2 . In all cases, prior to each experiment, the membrane was washed several times with distilled water until exhausting the free electrolyte inside the membrane and then was equilibrated with the solution used in the dilute compartment of the concentration cell. An inspection of the evolution of the curves in the figures shows that the emf of the concentration cell increases with time needing nearly $3 \mathrm{~h}$ in most cases to reach the maximum value and then decreases as time increases. The emf at the maximum of the curves was taken as the apparent electromotive force of the concentration cell flanked by electrolyte solutions with concentration $c_{2} / c_{1}$.

The emf of a concentration for an electrolyte $A_{v^{+}}^{z_{+}} B_{v^{-}}^{z_{-}} \rightarrow$ $v^{+} A^{z_{+}}+v^{-} B^{z_{-}}$is given by [12]

$$
e m f=\frac{\nu R T}{z_{+} F} \int_{a_{1}}^{a_{2}} t_{+}(c) d \ln a_{ \pm}=\frac{\nu R T}{F} \int_{a_{1}}^{a_{2}} \tau_{+}(c) d \ln a_{ \pm},
$$

where $a_{1}$ and $a_{2}$ are, respectively, the activities of the electrolyte solutions in the compartments 1 and 2 of the concentration cell, $t_{+}$and $\tau_{+}\left(=t_{+} / z_{+}\right)$are, respectively, the number of equivalents and moles of cations transported across the membrane by a Faraday of current, $F$, and $\nu=$ $\nu_{+}+\nu_{-}$is the total number of moles of ions proceeding from the dissociation of the electrolyte. For monovalent electrolytes, such as $\mathrm{HCl}$, (2) becomes

$$
e m f=-\frac{2 R T}{F} \int_{a_{1}}^{a_{2}} t_{+}(c) d \ln a_{ \pm} .
$$

Notice that for monovalent electrolytes, $t_{+}=\tau_{+}$. Since transport numbers depend on the concentration of electrolyte, solution of (3) requires measuring the $t_{+}(c)$ profile across the membrane using the Hirthoff method, that is, determining the variation of concentration of electrolyte in a concentration cell flanked by the electrolyte at the same concentration $c$ after passing a known amount of dc current across the membrane. However, if the concentration ratio $c_{2} / c_{1}$ is 2 or lower, the average transport number of the cation can approximately be estimated as

$$
t_{+}=\frac{e m f}{e m f_{\max }}
$$

where emf is the experimental value of the concentration cell and $e m f_{\text {max }}$ can be obtained doing $t_{+}=1$ in (3), that is,

$$
e m f_{\max }=-\frac{2 R T}{F} \ln \frac{a_{2}}{a_{1}} .
$$

Values of the apparent proton transport numbers for different concentrations flanking the membrane are shown in Figure 6.

The response of cation-exchange membranes in acid form to an alternating electric field of angular frequency $\omega$ is modeled by an electric circuit consisting of an ohmic resistance $R_{M}$ accounting for proton transport in the membrane

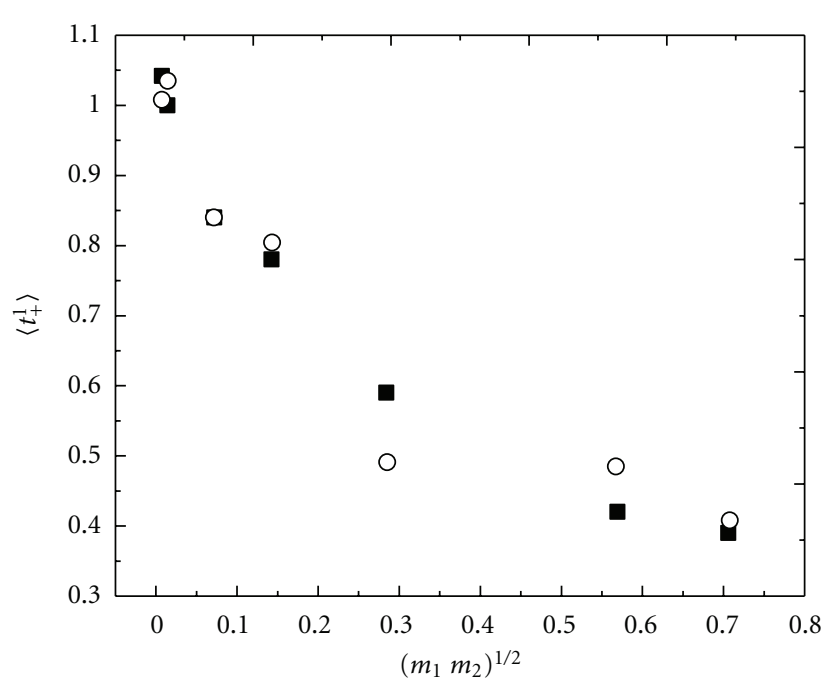

FIGURE 6: Variation of the apparent proton transport number with the geometric average of the molality of the solutions flanking the membrane in P5FNDIHS (squares) and C5FNDIHS (circles).

in series with a parallel RC circuit. The RC circuit represents a Debye relaxation process with a single relaxation time $\tau=$ RC. Strictly speaking, relaxation processes are described by a distribution of relaxation times and as a result it is more realistic to replace the capacitor by a constant phase element of admittance $Y^{*}(\omega)=Y_{0}(j \omega \tau)^{n}, \quad 0<n \leq 1$ [13]. The impedance of the circuit is given by

$$
Z^{*}(\omega)=R_{M}+\frac{R}{1+Y_{1}(j \omega \tau)^{n}},
$$

where $Y_{1}=R Y_{0}$ is a dimensionless parameter. The complex plane plot $Z^{\prime \prime}(\omega)$ versus $Z^{\prime}(\omega)$, called Nyquist diagram [14], is an arc intersecting the abscissa axis at $\omega \rightarrow \infty$ and $\omega \rightarrow 0$. Taking into account that $\lim _{\omega \rightarrow \infty} Z^{\prime}(\omega)=R_{M}$ and $\lim _{\omega \rightarrow \infty} Z^{\prime \prime}(\omega)=0$, the intersection of the arc with the abscissa axis at high frequencies gives the ohmic resistance of the membrane to proton transport. However, Nyquist plots for the acidic P5FNDIHS and C5FNDIHS membranes presented in Figures 7 and 8, respectively, show in addition to the polarization arc another arc, at higher frequencies, that presumably intersects with the abscissa axis at the origin. The real impedance where the two arcs intersect with the abscissa axis at the same point is the resistance $R_{M}$ of the membrane. On the other hand, the polarization arc in the low-frequency region does not intersect with the abscissa axis as (6) predicts but both $\left|Z^{\prime \prime}\right|$ and $Z^{\prime}$ increase as frequency decreases. This behavior is presumably associated with a charge-transfer resistance $R_{\mathrm{CT}}$ and a double-layer capacitance $C_{\mathrm{dl}}$. The Warburg impedance $[13,15,16]$ nearly always exhibits these two characteristics in such a way that it is conditioned by the diffusion of charges in the membrane-electrode interface. The value of this impedance for an interface of infinite thickness is given by

$$
Z_{W}^{*}(\omega)=\frac{\sigma}{\omega^{1 / 2}}-j \frac{\sigma}{\omega^{1 / 2}},
$$




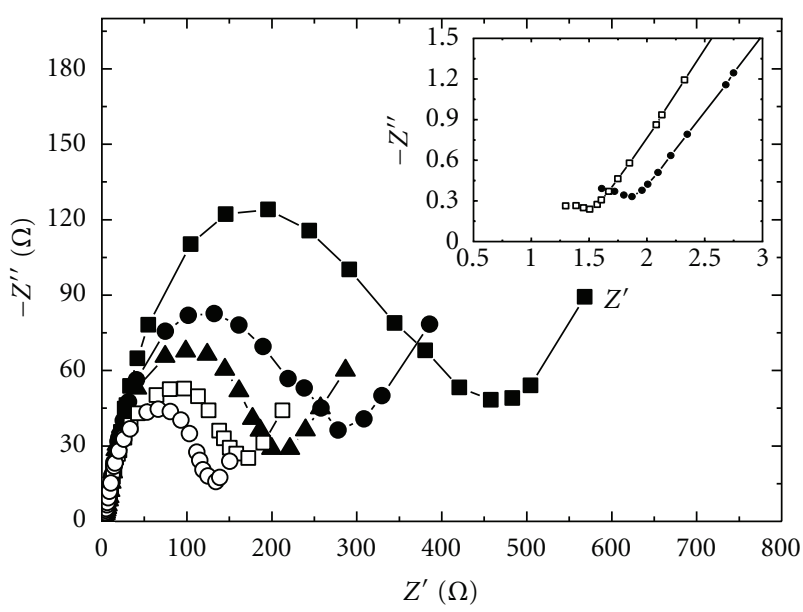

Figure 7: Nyquist plots at $10(\boldsymbol{\square}), 20(\bullet), 30(\boldsymbol{\Delta}), 40(\square)$ y $50^{\circ} \mathrm{C}$ (O) for the P5FNDIHS membrane in the acid form equilibrated with distilled water. Inset: zoom of the Nysquit plots at $20^{\circ} \mathrm{C}$ and $40^{\circ} \mathrm{C}$ in the high-frequency region.

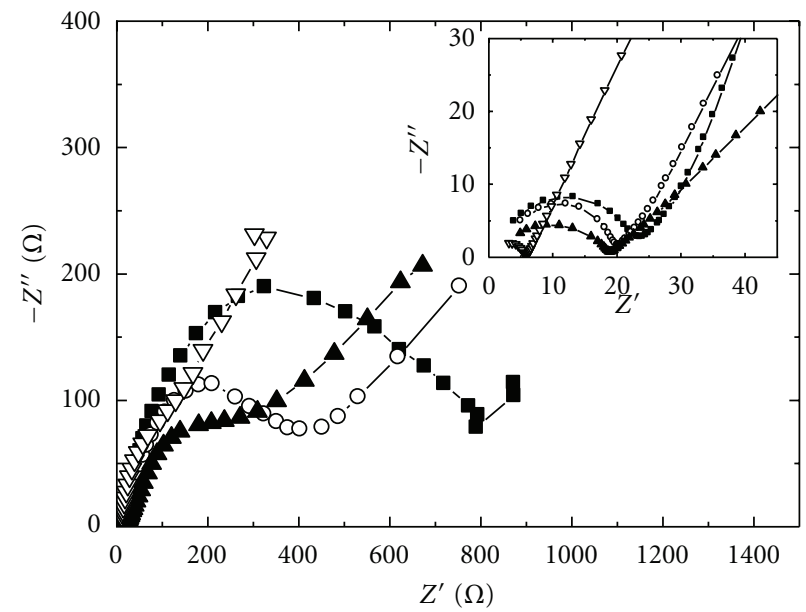

Figure 8: Nyquist plots at $20(\boldsymbol{\square}), 30(\bigcirc), 50(\boldsymbol{\Delta})$ y $70^{\circ} \mathrm{C}(\nabla)$ for the C5FNDIHS membrane in the acid form equilibrated with distilled water. Inset: zoom of the Nyquist plots at high frequencies.

where $\sigma$ is a constant that depends on $\Sigma_{i}\left(1 / C_{i}^{b} D_{i}^{1 / 2}\right)$ where $C_{i}^{b}$ and $D_{i}$ are, respectively, the bulk concentration and diffusion coefficients of the reactant species $i$. As a result the modulus of the impedance scales as $\left|Z_{W}^{*}(\omega)\right| \sim \omega^{-1 / 2}$, that is, the double logarithmic plot of the modulus of the complex impedance is a straight line of slope $-1 / 2$ in the case of a double layer of infinite thickness. Although the results seem to support the existence of a Warburg impedance, there are not enough data in the low-frequency region that allow to reach a definite conclusion concerning the membraneelectrode double layer thickness.

To account for the arc intersecting with the origin at high frequencies, the equivalent circuit of the membrane (ohmic resistance of the membrane in series with a circuit made up of constant phase element in parallel with the polarization resistance) should be in parallel with a capacitor, in the case of a semicircle, or a constant phase element for an arc.

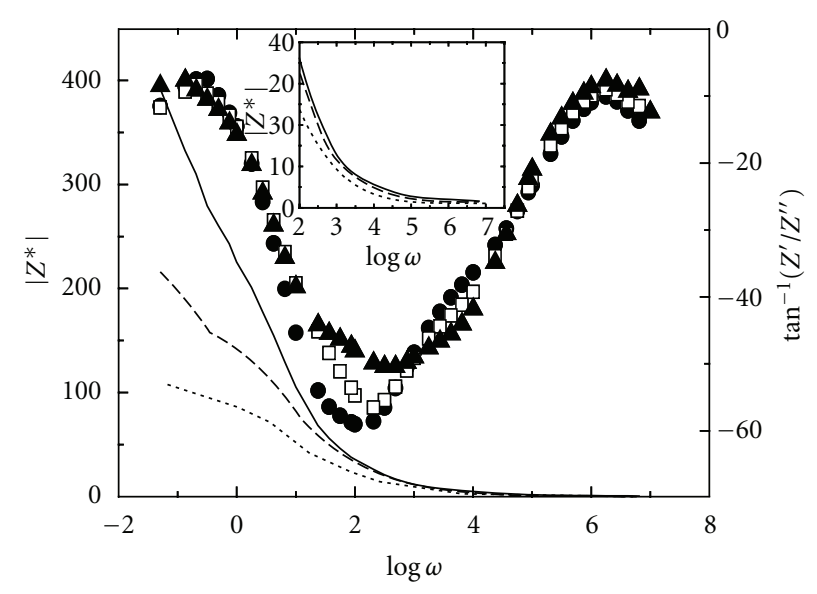

FIGURE 9: Bode diagram showing the variation of the modulus of the impedance $\left|Z^{*}\right|$ (lines) and the out-of-phase angle $(\phi=$ $\tan ^{-1} /\left(Z^{\prime \prime} / Z^{\prime}\right)$ (symbols) with the frequency at $20^{\circ} \mathrm{C}$ (solid line and filled circles), $40^{\circ} \mathrm{C}$ (dash line and open squares) and $60^{\circ} \mathrm{C}$ (dot line and filled triangles) for the P5FNDIHS membrane in the acid form equilibrated with distilled water.

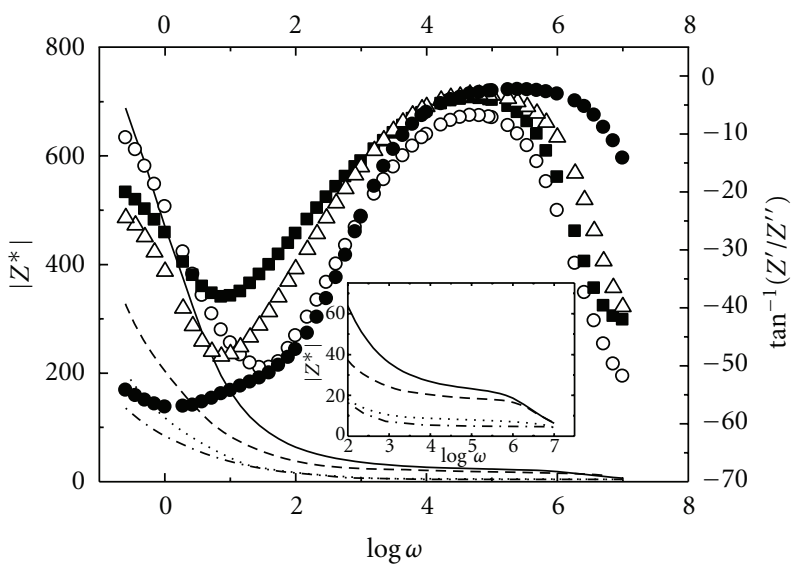

Figure 10: Bode diagram showing the variation of the modulus of the impedance $\left|Z^{*}\right|$ (lines) and the out-of-phase angle $(\phi=$ $\tan ^{-1} /\left(Z^{\prime \prime} / Z^{\prime}\right)$ (symbols) with the frequency at $20^{\circ} \mathrm{C}$ (solid line and filled circles), $40^{\circ} \mathrm{C}$ (dash line and filled squares), $60^{\circ} \mathrm{C}$ (dot line and open triangles), and $80^{\circ} \mathrm{C}$ (dash dot line and filled circles) for the C5FNDIHS membrane in the acid form equilibrated with distilled water.

An alternative method to determine the resistance of the membranes is the Bode diagram [17] consisting in the plot of both the modulus of the impedance and $\tan ^{-1}\left(Z^{\prime \prime} / Z^{\prime}\right)$ against frequency. According to (6),

$$
\begin{gathered}
\lim _{\omega \rightarrow 0}\left|Z^{*}(\omega)\right|=R_{p}+R_{M} ; \quad \lim _{\omega \rightarrow 0}\left|Z^{*}(\omega)\right|=R_{M}, \\
\phi=\lim _{\omega \rightarrow \infty} \tan ^{-1}\left[\frac{Z^{\prime \prime}(\omega)}{Z^{\prime}(\omega)}\right]=0 .
\end{gathered}
$$

Illustrative Bode plots for the P5FNDIHS and C5FNDIHS membranes are plotted in Figures 9 and 10, respectively. The curves show that the modulus of the impedance undergoes a sharp decrease reaching a plateau whereas $\phi$ reaches 
TABle 2: Comparative and illustrative results for the ohmic resistance, $R_{M}$, and conductivity, $\sigma$, of the membranes at $30^{\circ} \mathrm{C}$ obtained from Nyquist and Bode diagrams.

\begin{tabular}{lcccc}
\hline Membrane & $R_{M}$ (Nyquist), $\Omega$ & $R_{M}$ (Bode), $\Omega$ & $\sigma$ (Nyquist), S/m & $\sigma($ Bode), S/m \\
\hline P5FNDIHS & 1.79 & 1.70 & 2.13 & 2.24 \\
C5FNDIHS & 20.24 & 20.41 & 0.0135 & 0.0134 \\
\hline
\end{tabular}

a maximum at the plateau. The resistance of the membrane is taken as the value of $\left|Z^{*}(\omega)\right|$ at the maximum of $\phi$. It can be seen at very high frequencies that the modulus drops as a result of the fact that the capacitor in parallel with $R_{M}$ governs the impedance of the circuit. The results obtained for $R_{M}$ by the two methods are in rather good agreement. For examples the value of $R_{M}$ for the P5FNDIHS membrane at $30^{\circ} \mathrm{C}$ estimated from Nyquist and Bode plots are, respectively, 1.79 and $1.70 \Omega$. These results are 20.24 and $20.41 \Omega$ for the C5FNDIHS membrane (see Table 2). For consistency, the results of the Bode plots obtained for $R_{M}$ will be used in the analysis below.

The resistance $R_{M}$ of the membranes was measured at different temperatures and the corresponding conductivities were obtained by means of the familiar expression

$$
\sigma=\frac{l}{R_{0} S}
$$

where $l$ and $S$ are, respectively, thickness and area of the membrane in contact with the electrodes. For comparative purposes the values of the conductivity at $30^{\circ} \mathrm{C}$ are shown in Table 1. Illustrative Arrhenius plots showing the temperature dependence of the conductivity of the membranes obtained from the resistances of the membranes estimated from Bode plots are shown in Figure 11.

Figure 12 shows representative morphologies of the P5FNDIHS and C5FNDIHS membranes. The molecular chains of the latter membranes contain, respectively, $68 \%$ and $32 \%$ molar fractions of phenyl and 4oxybenzenesulfonic acid, 2,3,5,6-tetrafluorophenyl moieties bonded to the dicarboximide side groups. It is expected that these moieties are mutually incompatible and therefore segregations occur giving rise to nanosize domains observed in the AMF of C5FNDIHS. It is worth noting that the AFM of P5FNDIHS suggests a much more homogeneous membrane surface than that of C5FNDIHS. Moreover, it is expected that the surface of the dry P5FNDIHS and C5FNDIHS membranes has significant surface fluorine content compared to the theoretical bulky fluorine content owing to the low-surface energy of the tetrafluorophenyl moieties which provide a thermodynamic-driving force for the self-assembly at the surface air-polymer interface $[18,19]$.

In spite of the high water uptake of the P5FNDIHS membrane, the moles of water per anionic fixed group in the membrane, $\lambda$, are of the same order as that reported for Nafion [20] and copolyimide acid membranes [21, 22]. However, it is surprising that the value of $\lambda$ for the low IEC C5FNDIHS membrane is nearly four times that of the P5FNDIHS. This fact suggests that microphases separation in the latter membrane serves to compartmentalize an excess of water into the hydrophilic polar side chain domains,

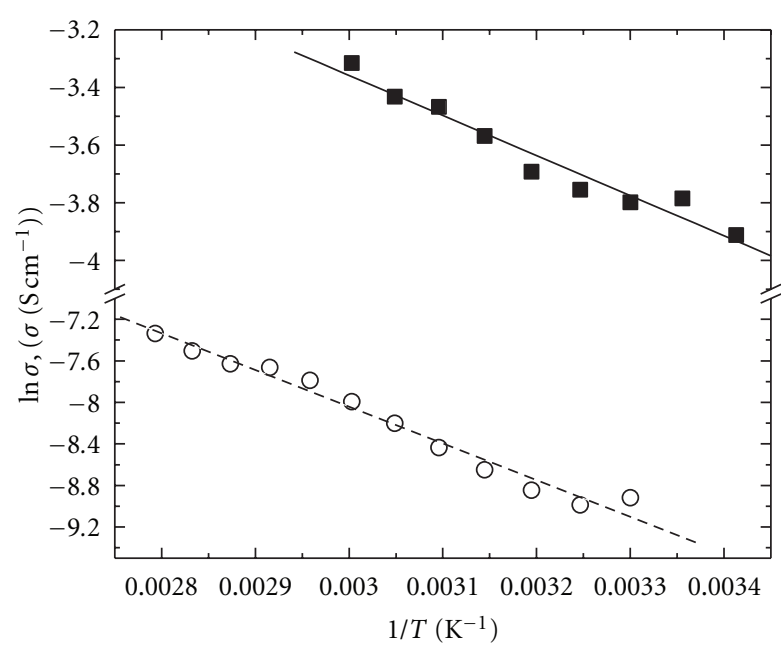

FIGURE 11: Arrhenius plot showing the temperature dependence of the P5FNDIHS (squares) and C5FNDIHS (circles) membranes.

specifically in the vicinity of the dicarboximide side groups. It is worth noting in this regard that apparently dried naphthalenic polyimides may contain up to $10 \%$ of water. Moreover, ${ }^{1} \mathrm{H}$ NMR experiments carried out on acidic naphthalenic polyimide membranes heated at $130^{\circ} \mathrm{C}$ under vacuum show peaks at $0.7-1 \mathrm{ppm}$ corresponding to water associated with imide groups [23]. This water may be absorbed by the membranes during the NMR experiments handling.

An inspection of the dependence of the electromotive force on time for the C5FNDIHS and P5FNDIHS membranes shows that a certain time is required to reach a maximum value and then decreases as time increases. The emf of the concentration cell containing the former membrane falls to zero. The change is not so dramatic for the concentration cell with the P5FNDIHS membrane. The drop of $t_{+}$to zero for the C5FNDIHS membrane at long times, even for dilute concentration solutions, suggests that the concentration of electrolyte equalizes in the two compartments of the concentration cell presumably as a consequence of strong electrolyte diffusion. The drop of $t_{+}$with increasing concentration is not so dramatic for the P5FNDIHS membrane at low concentrations, but the decrease of the transport parameter is still significant. To explain this behavior the membranes can be viewed formed by hydrophilic pores to the walls of which anionic $\mathrm{SO}_{3}{ }^{-}$groups are anchored. These groups prevent the diffusion of coions across the pores and therefore hinder electrolyte diffusion thus increasing the transport number of counterions. The strong dependence of the counterion transport on electrolyte concentration suggests that the number of anionic fixed groups in the walls is not large enough to 


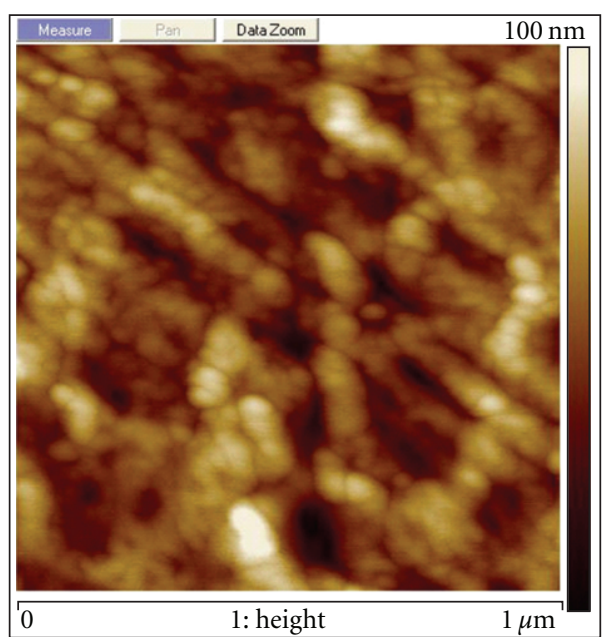

(a)

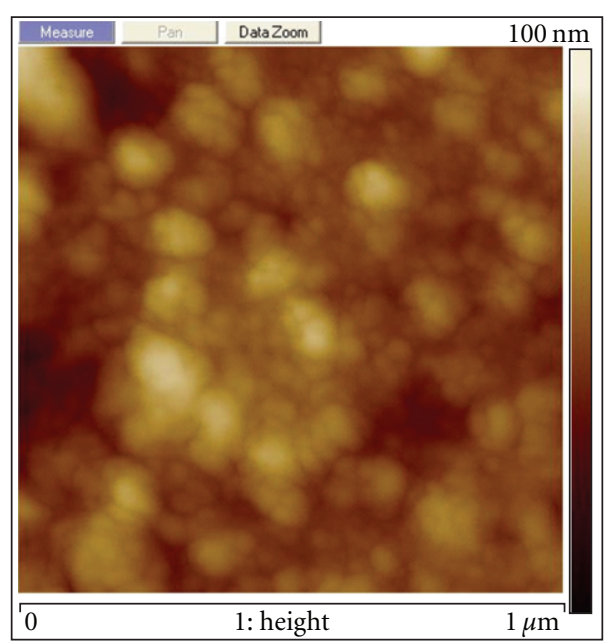

(b)

FIgURE 12: AFM topographic image for C5FNDHIS (a) and P5FNDIHS (b) membranes.

prevent coins diffusion across the membranes. As a result, electrolyte diffusion from the high-to the low-concentration compartment occurs, $c_{2} / c_{1}$ decreases, and the electromotive force of the concentration goes down. Owing to the rather high time necessary to reach a maximum and the rather high free ionic diffusion taking place in that period of time, the ratio $a_{2} / a_{1}$ presumably undergoes a significant decrease for the more concentrated solutions. Therefore, the emf at the maximum is the lower bound of this quantity and the transport number corresponding to the nominal values of $c_{2} / c_{1}$ should be higher than those obtained by means of (4).

The curves showing the variation of the transport number of protons with the geometrical average of the molality of the solutions flanking the membranes show that both membranes are ideally permselective for very dilute solutions, but the permselectivity undergoes a rather fast drop with increasing concentration. When the electrolyte solutions are flanking the membranes, protons in the concentrated $\mathrm{HCl}$ solution migrate to the side of the membrane facing the diluted $\mathrm{HCl}$ solution. Because fixed ions in the membrane hinder chloride anions transport across the membrane, the side of the membrane in contact with the concentrated $\mathrm{HCl}$ solution is negatively charged whereas that in contact with diluted $\mathrm{HCl}$ solution is positively charged. As a result an electric potential is created inside the membrane that drags the pore liquid positively charged toward the concentrated electrolyte solution compartment, enhancing the osmotic flow.

As the concentrations of the electrolyte solutions increase, chloride anions are not totally rejected by the fixed anions of the membrane, and diffusion of hydrochloric acid from the concentrated $\mathrm{HCl}$ solution compartment to the diluted $\mathrm{HCl}$ solution compartment occurs. Both the ionic diffusion across the membranes and the osmotic flow may be responsible for the low permselectivity of the membranes at high electrolyte solution concentration.

In an earlier work we carried out the synthesis of the nonfluorinated poly $(N$-phenyl-exo-endo-norbornene-5,6dicarboximide) which underwent nonuniform sulfonation of the phenyl groups by using acetyl sulfate as sulfonating agent [7]. The IEC of the membrane prepared from this ionic polynorbornene dicarboximide was $0.82 \mathrm{eq} / \mathrm{Kg}$ dry membrane and in spite of having a higher IEC, in comparison with that of the fluorine-containing C5FNDIHS membrane, the former membrane exhibited a water uptake of $0.124 \mathrm{Kg}$ $\mathrm{H}_{2} \mathrm{O} / \mathrm{Kg}$ dry membrane, about one-third of the value in this latter obtained by titration; additionally, the conductivity of the sulfonated membrane equilibrated with water was $0.0414 \mathrm{~S} / \mathrm{m}$, of the same order of that found for the fluorinecontaining C5FNDIHS membrane. These results suggest that the sulfonic acid groups have not relaxed the attractive interactions between phenyl groups and that molecular piling of the aromatic rings has taken place inhibiting the emergence of microphases separation in the non fluorinated membrane and therefore decreasing the storage of an excess of water into the polar side chain domains, specifically in the vicinity of the dicarboximide side groups. As it is seen, the chemical structure plays an important role in this kind of macromolecules since the more fluorine content in the polymer the more water uptake of the membrane. Indeed, an increase in the density of sulfonic acid affects directly the proportional transport properties in the membrane as it is shown in the fluorine-containing P5FNDIHS that exhibits the highest IEC, water uptake, and ionic conductivity of all the ionic polynorbornene dicarboximides we have discussed so far.

The conductivity of membranes with high water uptake is strongly dependent on the fixed ions concentration. Thus the P5FNDIHS membrane (average IEC $=1.90 \mathrm{eq} / \mathrm{Kg}$ dry membrane) exhibits a conductivity of $2.24 \mathrm{~S} / \mathrm{m}$, at $30^{\circ} \mathrm{C}$, of the same order of that reported for high-conductivity acidic membranes and about two orders of magnitude higher than that of the C5FNDIHS membrane (average IEC = $0.245 \mathrm{eq} / \mathrm{Kg}$ dry membrane). Despite the low permselectivity of the membranes at high electrolyte solution concentration, the rather high level of ionic conductivity as well as water content seems promising for low-temperature fuel cell applications. Arrhenius plots representing the temperature 
dependence of the membranes, presented in Figure 11, show that the activation of energy associated with proton transport across the P5FNDIHS membrane $(11.7 \pm 0.8 \mathrm{~kJ} / \mathrm{mol})$ is less than one half of that corresponding to the C5FNDIHS membrane $(29.3 \pm 1.6 \mathrm{~kJ} / \mathrm{mol})$.

The study of the mechanism governing proton transport in acidic ion-exchange membranes has drawn the attention of many researchers $[24,25]$. A $b$ initio simulations suggest that the proton state in bulk water and in water clusters fluctuates between more localized hydronium ion-like states or Eigen ions and more delocalized $\mathrm{H}_{5} \mathrm{O}_{2}^{+}$-like states or Zundel ions in such a way that forming and breaking hydrogen bonds in the neighborhood of the proton location (Grotthus like hoping) may be responsible for proton transport [26-30]. Proton diffusion involving this mechanism presumably takes place in high-conductivity membranes, such as, the P5FNDIHS membrane, is named structural diffusion. In low-conductivity membranes, such as, the C5FNDIHS membrane, water acts as a carrier of protons, and the transport is called vehicular diffusion.

\section{Conclusions}

The efficient segregation of hydrophilic from hydrophobic moieties, presumably favored by the low polarity of $\mathrm{C}^{\mathrm{ar}}-$ $\mathrm{F}$ bonds attached to the phenyl groups, gives rise to the formation of percolation paths responsible for the rather high proton conductivity of the homopolymeric membranes. The copolymeric membranes absorb an unusual quantity of water despite their low IEC. It seems that microphases separation in the membranes serves to compartmentalize an excess of water into the polar side chain domains, specifically in the vicinity of the dicarboximide side groups.

The electromotive force of the concentration cells undergoes a strong decrease at long times in the case of the homopolymeric membrane dropping to zero for the copolymeric membranes. The performance of the membranes in separation processes in diluted solutions is rather poor, unless the concentrations of the solutions at both sides of the membranes are continuously renewed.

\section{Abbreviations}

\begin{tabular}{|c|c|}
\hline 5FNDI: & $\begin{array}{l}N \text {-pentafluorophenyl-exo-endo-norbornene- } \\
5,6 \text {-dicarboximide }\end{array}$ \\
\hline$a:$ & Activity coefficient of the electrolyte solution \\
\hline AA: & Amic acid \\
\hline$C_{1}:$ & $\begin{array}{l}\text { Concentration of the solution in the diluted } \\
\text { compartment }\end{array}$ \\
\hline$C_{2}:$ & $\begin{array}{l}\text { Concentration of the solution in the } \\
\text { concentrated compartment }\end{array}$ \\
\hline C5FNDI: & $\begin{array}{l}\operatorname{Poly}(N \text {-pentafluorophenyl-norbornene-5,6- } \\
\text { dicarboximide-co- } N \text {-pentafluoropheny } \\
\text { l-exo-endo-norbornene-5,6-dicarboximide })\end{array}$ \\
\hline C5FNDIH: & Hydrogenated copolymer \\
\hline C5FNDIHS: & Copolymeric acid membrane \\
\hline emf: & Electromotive force \\
\hline$F:$ & Faraday constant \\
\hline
\end{tabular}

\begin{tabular}{|c|c|}
\hline IEC: & Ion exchange capacity \\
\hline$l:$ & $\begin{array}{l}\text { Thickness of the membrane in contact with } \\
\text { the electrodes }\end{array}$ \\
\hline$m:$ & Molality of the solution \\
\hline$m_{d}:$ & Weight of the dry membrane \\
\hline$m_{w}:$ & $\begin{array}{l}\text { Weight of the membrane equilibrated with } \\
\text { water }\end{array}$ \\
\hline NDA: & Norbornene-5,6-dicarboxylic anhydride \\
\hline P5FNDI: & $\begin{array}{l}\text { Poly }(N \text {-pentafluorophenyl-norbornene-5,6- } \\
\text { dicarboximide })\end{array}$ \\
\hline P5FNDIH: & Hydrogenated homopolymer \\
\hline P5FNDIHS: & Homopolymeric acid membrane \\
\hline PhNDI: & $\begin{array}{l}N \text {-phenyl-exo-endo-norbornene-5,6- } \\
\text { dicarboximide }\end{array}$ \\
\hline ROMP: & Ring opening metathesis polymerization \\
\hline$R_{M}:$ & $\begin{array}{l}\text { Ohmic resistance of the membrane to proton } \\
\text { transport }\end{array}$ \\
\hline$S:$ & $\begin{array}{l}\text { Area of the membrane in contact with the } \\
\text { electrodes }\end{array}$ \\
\hline$T_{d 1}:$ & Temperature of sulfonic group loss \\
\hline$T_{d 2}:$ & Temperature of main chain decomposition \\
\hline$T_{g}:$ & Glass transition temperature \\
\hline$t_{+}:$ & $\begin{array}{l}\text { Number of equivalents of cations } \\
\text { transported across the membrane by a } \\
\text { Faraday of current }\end{array}$ \\
\hline$W_{u}:$ & Water uptake \\
\hline$Z^{*}:$ & Impedance of the circuit \\
\hline$Z_{w}^{*}:$ & The Warburg impedance \\
\hline$\phi:$ & out-of-phase angle \\
\hline$\lambda:$ & $\begin{array}{l}\text { Moles of water per anionic fixed group in the } \\
\text { membrane }\end{array}$ \\
\hline$v:$ & Total number of moles of ions \\
\hline$\rho:$ & Density of the membrane \\
\hline$\sigma:$ & Conductivity of the membrane in acid form \\
\hline$\tau_{+}:$ & $\begin{array}{l}\text { Number of moles of cations transported } \\
\text { across the membrane by a Faraday of current }\end{array}$ \\
\hline$\omega:$ & $\begin{array}{l}\text { Angular frequency of an alternating electric } \\
\text { field. }\end{array}$ \\
\hline
\end{tabular}

\section{Acknowledgments}

The authors thank CONACYT-SEMARNAT, CONACYTFORDECYT, and ICyTDF for generous support with contracts 23432, 116157, and 4312. The authors are grateful to Alejandrina Acosta, Carlos Flores Morales, and Miguel Ángel Canseco for their assistance in NMR, AFM, and thermal properties, respectively. This work was also supported by the CICYT through the Project MAT2011-29174-C02-02.

\section{References}

[1] T. Sata, Ion-Exchange Membranes, RSC, Cambridge, UK, 2004.

[2] T. Xu, "Ion exchange membranes: state of their development and perspective," Journal of Membrane Science, vol. 263, no. 1-2, pp. 1-29, 2005.

[3] M. A. Hickner, H. Ghassemi, Y. S. Kim, B. R. Einsla, and J. E. McGrath, "Alternative polymer systems for proton exchange membranes (PEMs)," Chemical Reviews, vol. 104, no. 10, pp. 4587-4612, 2004. 
[4] A. P. Contreras, M. A. Tlenkopatchev, M. M. López-González, and E. Riande, "Synthesis and gas transport properties of new high glass transition temperature ring-opened polynorbornenes," Macromolecules, vol. 35, no. 12, pp. 4677-4684, 2002.

[5] M. Tlenkopatchev, J. Vargas, M. A. Almaraz-Girón, M. LópezGonzález, and E. Riande, "Gas sorption in new fluorine containing polynorbornenes with imide side chain groups," Macromolecules, vol. 38, no. 7, pp. 2696-2703, 2005.

[6] J. Vargas, A. A. Santiago, M. A. Tlenkopatchev, M. LópezGonzález, and E. Riande, "Gas transport in membranes based on polynorbornenes with fluorinated dicarboximide side moieties," Journal of Membrane Science, vol. 361, no. 1-2, pp. 78-88, 2010.

[7] J. Vargas, A. A. Santiago, M. A. Tlenkopatchev et al., "Gas transport and ionic transport in membranes based on polynorbornenes with functionalized imide side groups," Macromolecules, vol. 40, no. 3, pp. 563-570, 2007.

[8] A. A. Santiago, J. Vargas, S. Fomine, R. Gaviño, and M. A. Tlenkopatchev, "Polynorbornene with pentafluorophenyl imide side chain groups: synthesis and sulfonation," Journal of Polymer Science A, vol. 48, no. 13, pp. 2925-2933, 2010.

[9] D. O’Hagan, "Understanding organofluorine chemistry. An introduction to the C-F bond," Chemical Society Reviews, vol. 37, no. 2, pp. 308-319, 2008.

[10] Y. P. Yampol'skii, N. B. Bespalova, E. S. Finkel'shtein, V. I. Bondar, and A. V. Popov, "Synthesis, gas permeability, and gas sorption properties of fluorine-containing norbornene polymers," Macromolecules, vol. 27, no. 10, pp. 2872-2878, 1994.

[11] A. A. Santiago, J. Vargas, J. Cruz-Gómez et al., "Synthesis and ionic transport of sulfonated ring-opened polynorbornene based copolymers," Polymer, vol. 52, no. 19, pp. 4208-4220, 2011.

[12] V. Compañ, F. J. Fernández-Carretero, E. Riande, A. Linares, and J. L. Acosta, "Electrochemical properties of ion-exchange membranes based on sulfonated EPDM-polypropylene blends," Journal of the Electrochemical Society, vol. 154, no. 2, pp. B159-B164, 2007.

[13] E. Barsoukov and J. R. Macdonalds, Impedance Spectroscopy: Theory, Experiment and Applications, chapter 2, Wiley, Hoboken, NJ, USA, 2nd edition, 2005.

[14] H. Nyquist, "Thermal agitation of electric charge in conductors," Physical Review, vol. 32, no. 1, pp. 110-113, 1928.

[15] E. Warburg, "About the behaviour of so-called impolarizable electrodes in the presence of alternating current," Annals of Physics and Chemistry, vol. 67, p. 493, 1899.

[16] A. J. Bard and L. R. Faulkner, Electrochemical Methods. Fundamentals and Applications, section 10.3, Wiley, 2nd edition, 2001.

[17] W. W. Bode, Network Analysis in Feedback Amplifier Design, Van Nostrand, Princenton, NJ, USA, 1956.

[18] S. Wu, Polymer Interface and Adhesion, chapter 5, Marcel Dekker, New York, NY, USA, 1982.

[19] H. Ghassemi, J. E. McGrath, and T. A. Zawodzinski Jr., "Multiblock sulfonated-fluorinated poly(arylene ether)s for a proton exchange membrane fuel cell," Polymer, vol. 47, no. 11, pp. 4132-4139, 2006.

[20] R. O'Hayre, S.-W. Cha, W. Colella, and F. B. Prinz, Fuel Cell Fundamentals, chapter 4, Wiley \& Sons, New York, NY, USA, 2006.

[21] X. Guo, F. Zhai, J. Fang, M. F. Heras-Laguna, M. LópezGonzález, and E. Riande, "Permselectivity and conductivity of membranes based on sulfonated naphthalenic copolyimides," Journal of Physical Chemistry B, vol. 111, p. 13694, 2007.

[22] S. Yuan, C. del Rio, M. López-González, X. Guo, J. Fang, and E. Riande, "Impedance spectroscopy and performance of crosslinked new naphthalenic polyimide acid membranes," Journal of Physical Chemistry C, vol. 114, no. 51, pp. 22773-22782, 2010.

[23] L. Garrido, J. Pozuelo, M. López-González, J. Fang, and E. Riande, "Simulation and experimental studies on proton diffusion in polyelectrolytes based on sulfonated naphthalenic copolyimides," Macromolecules, vol. 42, no. 17, pp. 6572-6580, 2009.

[24] S. J. Paddison, "Proton conduction mechanisms at low degrees of hydration in sulfonic acid-based polymer electrolyte membranes," Annual Review of Materials Research, vol. 33, pp. 289319, 2003.

[25] K. D. Kreuer, S. J. Paddison, E. Spohr, and M. Schuster, “Transport in proton conductors for fuel-cell applications: simulations, elementary reactions, and phenomenology," Chemical Reviews, vol. 104, no. 10, pp. 4637-4678, 2004.

[26] M. Tuckerman, K. Laasonen, M. Sprik, and M. Parrinello, "Ab initio molecular dynamics simulation of the solvation and transport of hydronium and hydroxyl ions in water," The Journal of Chemical Physics, vol. 103, no. 1, pp. 150-161, 1995.

[27] M. Tuckerman, K. Laasonen, M. Sprik, and M. Paraniello, "Ab initio molecular dynamics simulation of the solvation and transport of $\mathrm{H}_{3} \mathrm{O}^{+}$and $\mathrm{OH}^{-}$ions in water," Journal of Physical Chemistry, vol. 99, p. 5749, 1995.

[28] M. E. Tuckerman, D. Marx, M. L. Klein, and M. Parrinello, "On the quantum nature of the shared proton in hydrogen bonds," Science, vol. 275, no. 5301, pp. 817-820, 1997.

[29] D. Marx, M. E. Tuckerman, J. Hutter, and M. Parrinello, "The nature of the hydrated excess proton in water," Nature, vol. 397, no. 6720, pp. 601-604, 1999.

[30] D. Marx, M. Tuckerman, and M. Paraniello, "Solvated excess protons in water: quantum effects on the hydration structure," Journal of Physics, vol. 12, no. 8, pp. A153-A159, 2000. 

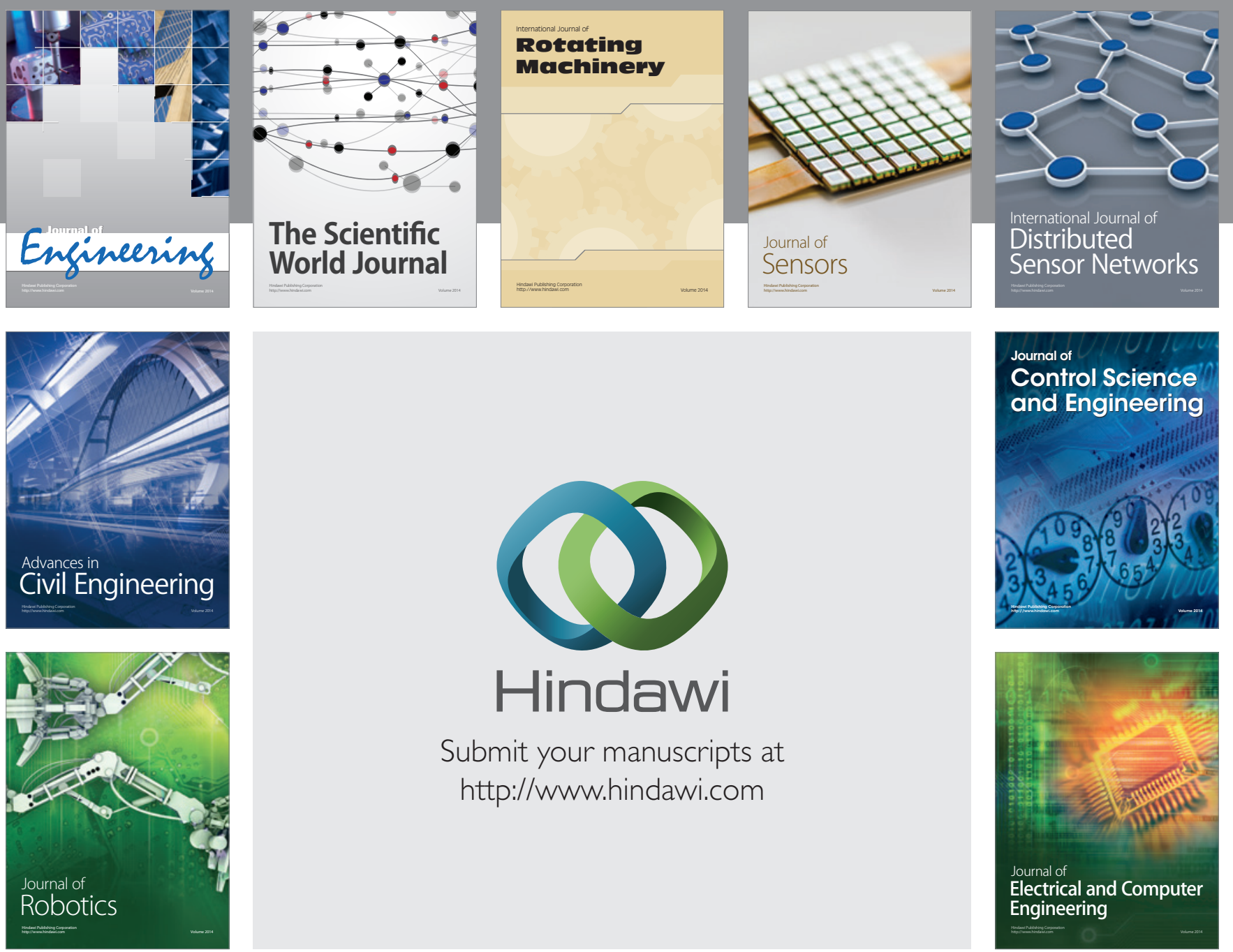

Submit your manuscripts at

http://www.hindawi.com
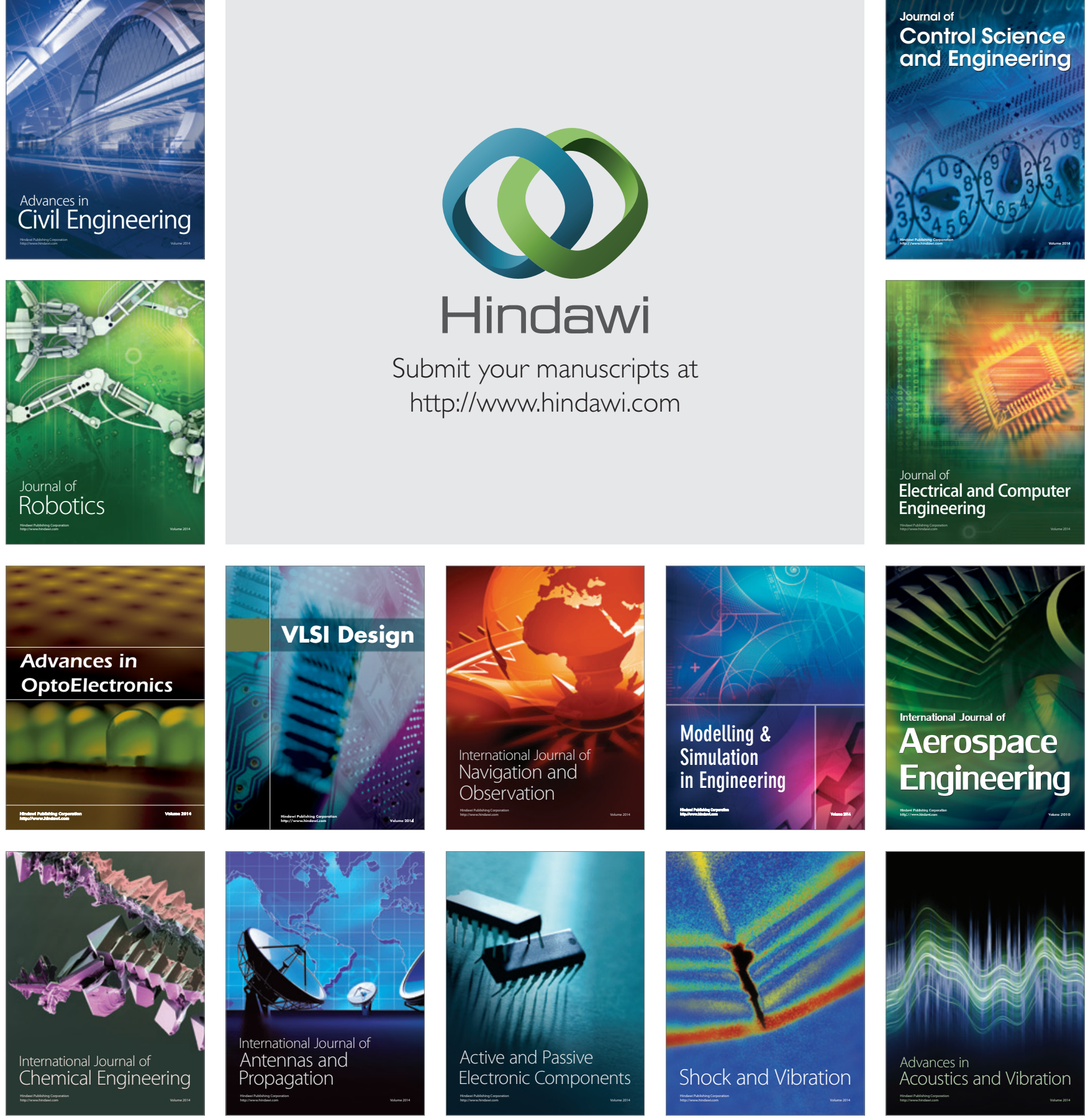